\title{
Teknik Sinema Edukasi untuk Meningkatkan Empati pada Siswa SMP Pelaku Perundungan
}

\author{
Amallia Putri Kartika Sari, Nanik Prihartanti, Zahrotul Uyun
}

\author{
Magister Psikologi Profesi \\ FakultasPsikologi, Universitas Muhammadiyah Surakarta \\ Jl. Garuda Mas No.3-7, Gatak, Pabelan, Kec.Kartasura, KabupatenSukoharjo, Jawa Tengah 57169 \\ amalliaputri72@yahoo.com
}

\begin{abstract}
Abstrak
Teknik Sinema Edukasi ini bertujuan untuk menguji pengaruh pelatihan teknik sinema edukasi efektif untuk menungkatkan empati pada siswa SMP pelaku perundungan. Keseluruhan subjek dalam penelitian berjumlah 30 siswa yang memiliki empati rendah dengan rerata usia 13-14 tahun, dibagi dalam 2 kelompok yaitu eksperimen dan kontrol. Keduanya tidak dikelompokkan secara acak (non random assignment). Metode pengumpulan data menggunakan skala empati dengan validitas sebesar 0,80 dengan $p=0,040$ dan reliabilitas 0,891 . Penelitian ini menggunakan metode Quasi Experimental Design dengan desain pretest-postest control group design. Uji hipotesis menggunakan Man Whitney U-Test dengan nilai $z=-4.706$, nilai Asymp. Sig. (2-tailed) 0, 813 (p>0.05) yang artinya terdapat perbedaan tingkat empati yang signifikan antara kelompok eksperimen dan kelompok kontrol setelah diberikan pelatihan teknik sinema edukasi. Hal tersebut sesuai dengan hipotesis pada penelitian ini yakni pelatihan teknik sinema edukasi efektif meningkatkan empati pada siswaSMP pelaku perundungan. Ada 4 sesi dalam pelatihan ini yang berpengaruh dalam peningkatan empati pada peserta intervensi yakni "bagaimana empatiku, mendalami empati, strategi penyelesaian konflik dan rencana tindakan". Sesi tersebut mewakili aspek-aspek yang ada dalam empati.
\end{abstract}

Kata kunci: Psikologi;Empati; Pelaku Perundungan; Sinema Edukasi; Pelatihan.

\begin{abstract}
Abstrack
The educational cinema technique aims to test the influence of effective educational cinema engineering training to provide empathy to JUNIOR students of abuse. The overall subject in the study amounted to 30 students who had low empathy with the average age of 13-14 years, divided into 2 groups of experiments and controls. Both are not randomly grouped (non random assignment). The data collection method uses an empathy scale with a validity of 0.80 with $\mathrm{P}=$ 0,040 and reliability of 0.891 . This research uses Quasi Experimental Design method with Pretest-postest design control group design. Test the hypothesis using Man Whitney U-Test with the value $z=-4,706$, the value of ASYMP. Sig. (2-tailed) $0,813(\mathrm{p}>0.05)$ which means there is a significant difference in the level of empathy between the experiment group and the control group after being given educational cinema engineering training. This is in accordance with the hypothesis on this study, which is an effective educational cinema engineering training to improve empathy to the siswaSMP abuse. There are 4 sessions in this training that have an effect on increasing empathy for the intervention participants, namely "How my masters, deepen empathy, conflict resolution strategies and action plans". The session represents the aspects that exist in empathy.
\end{abstract}

Keywords: Psychology; Empathy; Abuser Bullying; Educational Cinema; Training.

\section{PENDAHULUAN}

Perundungan dijabarkan sebagai sebuah tindakan penindasan atau perilaku agresif terjadi berulang-ulang, dilakukan kepada orang yang lebih kuat ke yang lemah serta dapat menyebabkan masalah fisik maupun psikologis (Irel, 2017). Prevalensi perundungan fisik di Amerika Serikat 
sebanyak 53, 6 \% (Wang, Iannotti, \& Nansel, 2009). United States bagian Departemen Pendidikan merilis informasi bahwa pada tahun 2015 remaja usia 12-18 tahun menjadi koban perundungan di lingkungan pendidikan dan sosial media dengan prevalensi sebanyak $22 \%$ (Lessne \& Cidade, 2015). Tahun 2012 di Cina tingkat prevalensi pelaku perundungan yang terjadi di sekolah bervariasi diantaranya $8 \%$ di daratan Cina, $40-71 \%$ di Taiwan dan $19-52 \%$ di Hong Kong (Chan $\&$ Wong, 2015). Yayasan Sejiwa tahun 2008 melakukan penelitian tentang tingkat perundungan pada beberapa wilayah di Indonesia Yogyakarta, Surabaya, dan Jakarta hasilnya adalah masalah kekerasan masih mendominasi terbanyak pada siswa SMA sebesar $67,9 \%$ sedangkan pada siswa SMP sebesar 32,1\% (Rismawan, 2016).

Peneliti mengambil data awal dengan menggunakan data pada kasus kelompok Praktek Kerja Profesi Psikologi yang dilakukan tahun 2018 di Sekolah Menengah Pertama X di Kartasura. peneliti memberikan kuesinoner berbentuk "self report" yang diberikan pada beberapa kelas dengan total responden 208 orang di SMP X Kartasura, hal ini bertujuan untuk mengidentifikasi terdapat fenomena permasalahan perundungan seperti yang dikeluhkan oleh pihak sekolah. Bentuk-bentuk perundungan yang diungkap dalam kuesinoner berbentuk "self report"terdiri dari perundungan fisik, verbal dan relasional. Data yang ada dioleh dengan membuatan kategorisasi dengan menetapkan kriterianya terlebih dahulu. 3 kategori (rendah, sedang, tinggi) (Azwar, 2012).

Hasil kuesioner akan di deskripsikan berdasarkan jenjang kelas, berikut ini adalah tabel hasil perilaku perundungan pada kelas 7,8 dan 9 sebagai berikut :

Tabel 1

FenomenaPerundungan di Kelas 7,8 dan 9

\begin{tabular}{ccc}
\hline Kategorisasi Skor & $\begin{array}{c}\text { Jumlah } \\
\text { Siswa }\end{array}$ & $\begin{array}{c}\text { Persentase } \\
(\%)\end{array}$ \\
\hline Rendah (0-40) & 95 & $46 \%$ \\
\hline Sedang (40-80) & 81 & $39 \%$ \\
\hline Tinggi (80-120) & 32 & $15 \%$ \\
\hline TOTAL & $\mathbf{2 0 8}$ & $\mathbf{1 0 0}$
\end{tabular}

Peneliti merasa perlu adanya informasi lebih lanjut untuk menentukan pelaku perundungan di sekolah tersebut dengan memberikan skala perundungan yang dibuat oleh Purnama (2017). Validitas skala tersebut berikisar 0,303 s/d 0,696 $(\mathrm{p}<0,005)$ dan realibilitas $=0,868$. Skala terdiri dari 3 aspek perundungan yakni fisik, verbal dan psikologis dengan total 45 aitem. Skala diberikan kepada 164 siswa dari kelas 7 dan 8. Data yang ada dioleh dengan membuatan kategorisasi berdasarkan Azwar (2012) menjelaskan bahwa langkah pertama pembuatan kategorisasi dengan menetapkan kriterianya terlebih dahulu. 3 kategori (rendah, sedang, tinggi).

Tabel 2

\begin{tabular}{|c|c|c|c|}
\hline \multicolumn{4}{|c|}{ Hasil Screening Skala Perundungan } \\
\hline Kelas & Kategori & Range & Jumlah Siswa \\
\hline \multirow[t]{2}{*}{8} & Rendah & $>90$ & 26 \\
\hline & Sedang & $90-135$ & 18 \\
\hline \multirow[t]{2}{*}{7} & Tinggi & $<135$ & 120 \\
\hline & Total & \multicolumn{2}{|r|}{164} \\
\hline
\end{tabular}

Selain data kuantitatif maka peneliti melengkapi data awal dengan hasil kualitatif dengan wawancara yakni diperoleh hasil bentuk perundungan yang terjadi di sekolah adalah perundungan 
verbal dan fisik. Perundungan verbal yang sering terjadi adalah ejekan kepada teman seperti mengejek nama orang tua, mengejek fisik anak, mengejek nama panggilan nama anak. Bentuk perundungan fisik yang terjadi lebih kepada siswa yang di ejek membalas karena karena terus menerus di ejek sehingga tidak mampu menahan emosi dan merespon dengan cara memukul, menendang akan tetapi mayoritas dari pelaku tidak mengetahui akibatnya seperti apa. Wakil kepala bidang kesiswaan mejelaskan bahwa motif dari merundung temannya yakni karena dulunya ada yang menjadi korban perundungan lalu memiliki kesempatan untuk membalas dendam, ada beberapa siswa yang menjadi pelaku perundungan karena ikut-ikutan temannya agar dipandang menakutkan dan memiliki kekuatan untuk berkuasa serta karena mereka melihat perilaku temanteman dikelas yang sudah biasa melakukan perundungan kepada teman lain di kelas.

Terdapat faktor internal dan eksternal penyebab terjadinya kasus perundungan pada remaja. Pada faktor faktor internal remaja melakukan perilaku perundungan yakni diantaranya: a) Gender, b) Usia, c) Tingkat agresivitas, d) Achievement dan e) Empati yang rendah.) Prestasi sekolah, d) Kepribadian (Zakiyah, Humaedi, \& Santoso, 2017). Empati menjadi salah satu alasan yang menyebabkan munculnya perilaku perundungan bagi remaja. Hal tersebut di dukung oleh penelitian tentang empati salah satunya menjelaskan bahwa pelaku perundungan tidak memiliki sikap empati hal tersebut dikarenakan ia cenderung memiliki kemarahan dan terindikasi terlibat dalam tindak kriminal (Hawker \& Boulton, 2014). Empati berkontribusi penting dalam munculnya perilaku perundungan. Menurut (Zakiyah, Humaedi, \& Santoso, 2017) empati didefinisikan sebagai kemampuan seseorang untuk memahami oranglain dalam hal emosi, pikiran dan sikap. Empati mengandung dua konsep, yaitu kognitif dan afektif. Empati adalah kemampuan afektif yang berfungsi untuk memahami dan merasakan emosi orang lain pada peristiwa tertentu. (Machackova \& Pfetsch, 2016). Empati berfungsi sebagai kemampuan seseorang untuk memahami situasi emosional dari orang lain (Machackova \& Pfetsch, 2016) anak-anak dan remaja yang memiliki pengalaman untuk menunjukkan perasaan empati terbukti secara positif dapat membantu korban perundungan melawan pelaku perundungan, dalam penelitiannya ia telah menemukan keterkaitan yang positif antara respons emosional terhadap kepekaaan munculnya empati terhadap orang lain saat menyaksikan perundungan pada orang lain (Machackova \& Pfetsch, 2016).

Empati membawa angin segar untuk mencegah perilaku perundungan. Empati didefinisikan sebagai usaha seseorang agar dapat merasakan situasi atau perasaan emosional orang lain. Sehingga ia mampu untuk menempatkan sikap dan perilakunya dengan berdasarkan pada sudut pandang oranglain agar menjadi lebih peduli dan mencegah perilaku perundungan (Fikrie, 2016). Penyebab munculnya perilaku perdunungan karena beberapa hal yakni perasaan balas dendam korban, tradisi/budaya, karakteristik korban dan sikap ingin berkuasa dan empati yang rendah (Fikrie, 2016). Empati yang rendah menyebabkan para pelaku kurang memahami keadaan korban bahkan tidak peduli atau cenderung melakukan kekerasaan (Fikrie, 2016). Beberapa penelitian yang menujukkan bahwa kasus perundungan dapat ditangani dengan adanya pelatihan untuk meningkatkan empati salah satunya yakni "Pengaruh Program Pembangunan Empati Terhadap Perilaku Perundungan" hasilnya adalah program pengembangan empati menunjukkan hasil yang efektif untuk menurunkan perilaku perundungan (Stanbury, 2009). Hasil penelitia tesis dengan salah satu variabelnya menggunakan empati menunjukan bahwa pelatihan empati berhasil mengurangi perilaku perundungan pada siswa SMK. Peneliti memberikan bekal kepada peserta untuk belajar berperilaku asertif dan memunculkan empati pada orang lain (Wewengkang, 2018). Hasil Praktek Kerja Profesi Psikologi dari (Sari, Joefiani, Gimmy, \& Siswadi, 2015) menunjukan dengan pelatihan psikoedukasi dapat mengurangi perundungan di tingkat SMP. 
Sinema adalah metode penyampaian film yang berisikan pola perilaku, tema, tokoh dan adegan) yang dapat dianalisis dengan metode modelling dalam dunia psikologi dan dapat digunakan sebagai untuk mengajar (Tri, 2017). Sinema atau film mampu menunjukkan karakter, bentuk perilaku serta tema yang diangkat sehingga menarik untuk di amati (Wu, 2008). Film ini dapat diterapkan kepada siswa sebagai sebuah terapi (cinematherapy) (Tri, 2017). Bryne (2003) menjelaskan bahwa empati seseorang akan muncul ketika ia melihat karakter fiktif dalam film yang menyerupai kehidupan sehari-hari, misalnya melihat peran tokoh korban perundungan. Setelah melihat film maka akan memunculkan perasaan efek positif. Oleh karena itu menonton film dapat memberikan efek positif yang dapat meningkatkan empati (Niemiec, 2011). Hasil penelitian yang dilakukan Tri (2017) memaparkan bahwa sinema terapi dapat meningkatkan empati siswa. Kelebihan lainnya yakni peserta akan bertambah wawasan dan pengetahuan tentang emoati dan penerapannya dalam kehidpan sehari-hari melalui metode diskusi.

Hipotesis pada penelitian ini adalah pelatihan teknik sinema edukasi efektif meningkatkan empati pada siswaSMP. Adapun dilakukannya penelitian yakni menguji efektivitas pemberian teknik sinema edukasi untuk meningkatkan empati pada siswa pelaku perundungan.

\section{METODE}

Teknik Sinema Edukasi penelitian eskperimen dengan metode quasi experimental design, dengan desain pretest-postest control group design. Desain dibagi menjadi dua bagian (eksperimen dan kontrol). Keduanya tidak di kelompokkan secara acak (non random assignment), untuk kemudian diukur dua kali, pretest dan postest (Y1 dan Y2). Perlakuan (X) hanya diberikan pada kelompok eksperimen saja (Creswell, 2015).

Tabel 3

RancanganPenelitianEksperimen

\begin{tabular}{llll}
\hline & Pretest & Perlakuan & Posttest \\
\hline Eksperimen & Y1 & $\mathrm{X}$ & Y2 \\
\hline Kontrol & Y1 & X0 & Y2 \\
\hline
\end{tabular}

\section{Keterangan :}

Y1 : Pemberian skala empati (pretest)

Y2 : Pemberian skala empati (posttest)

$\mathrm{X} \quad$ : Perlakuan pemberian teknik sinema edukasi

X0 : Tanpa perlakuan

Populasi pada penelitian ini adalah kelompok siswa dari SMP Muhammadiyah 1 Kartasura. Teknik pemilihan sample menggunakan purposive random sampling. Karakteristik tersebut yaitu sebagai berikut :

1. Remaja awal berusia 12-15 tahun.

2. Siswa SMP Muhammadiyah 1 Kartasura

3. Memiliki skor empati yang rendah

4. Menjadi pelaku perundungan

5. Bersedia mengisi lembar persetujuan untuk mengikuti seluruh kegiatan psikoedukasi agar peserta dapat menjadi peserta aktif. 
Screening subjek dilakukan dengan menggunakan alat ukur skala empati yang dibuat oleh peneliti berdasarkan aspek Davis (1983) yaitu: Perspective Taking, Fantasy, Empathy Concern, Personal Distress.Dari hasil screening diketahui jumlah keseluruhan subjek adalah 30 yang dibagi menjadi 2 bagian yakni kelompok eksperimen 15 subjek dan 15 subjek pada kelompok kontrol. Metode pengumpulan data dalam penelitian ini menggunakan skala, observasidan dokumentasi.Hasil validitas skala adalah 0,80 dengan $\mathrm{p}=0,040$ (Aiken, 1985) dan reliabilitas menggunakan Cronbach Alpha. Alpha yang diperoleh sebesar 0,891<0,06. Artinya skala tersebut dinyatakan reliabel untuk dipakai dalam pengukuran empati siswa SMP (Sujarweni, 2014). Uji hipotesis dalam penelitian ini menggunakan teknik Man Whitney U-Test. Berikut adalah beberapa contoh aitem skala yang digunakan dalam penelitian ini "Saya tidak peduli pada teman yang sedang saya rundung", "Saya ikut terlibat ketika ada aksi perundungan di sekitar saya" dan "Saya sangat kasihan melihat teman saya kesakitan karena menjadi korban perundungan".

Sementara uji validitas modul dilakukan oleh expert judgement. Proses expert judgement dilakukan oleh lima ahli dengan memberikan dua penilaian, yang pertama menilai validitas sesi tiap modul dan yang kedua menilai modul dari berbagai aspek yakni bahasa, alur ketepatan intervensi, durasi per kegiatan, koherensi antar sesi, ketepatan teori, total waktu intervensi, alat dan bahan serta kejelasan instruksi. Hasilnya adalah semua sesi dalam penilaian mendapatkan skor dari 4,2 hingga 4,8 dari range skor 1-5 skor tinggi artinya modul tersebut layak untuk digunakan pada penelitian ini (Azwar, 2012).

\section{HASIL}

Penelitian ini dilakukan untuk mengetahui efektivitas pemberian teknik sinema edukasi untuk meningkatkan empati pada siswa SMP pelaku perundungan. Berdasarkan analisis uji hipotesis maka diperoleh hasil bahwa pemberian pelatihan teknik sinema edukasi efektif meningkatkan empati pada siswa smp pelaku perundungan.

Hasil uji normalitas dengan menggunakan Kolmogorov-smirnov nilai signifikansi Asiymp.Sig (2-tailed) pada kelompok Pretest eksperimen dan kontrol sebesar 0,003 dan 0,020 lebih kecil dari pada nilai probabilitas $(0,05)$. Begitu juga pada nilai signifikansi Asiymp.Sig (2tailed) pada kelompok Posttest eksperimen dan kontrol sebesar 0,019 dan 0,004 lebih kecil dari pada nilai probabilitas $(0,05)$, hal tersebut sesuai dengan aturan dalam uji normalitas Kolmogorovsmirnov, maka kesimpulannya data berdistribusi tidak normal.Hasil uji homogenitas menunjukkan nilai signifikansi untuk pretest kelompok eksperimen dan kelompok kontrol sebesar 0,032.Karena nilai sig. $0,032<0,05$. Hal tersebut sesuai dengan aturan dalam uji homogentas, maka kesimpulannya varians data pretest pada kelompok eksperimen dan kelompok kontrol adalah heterogen.

Pada penelitian ini karena data berdistribusi tidak normal dan heterogen maka analisis yang digunakan adalah non paramterik dengan menggunakan Mann Whitney dan Wilcoxon. Uji Mann Whitney dari skor posttest pada kelompok eksperimen dan kelompok kontrol menunjukkan nilai $\mathrm{Z}$ sebesar -4.706, nilai Asymp. Sig. (2-tailed) sebesar .000 $(\mathrm{p}<0.05)$ sehingga hasilnya adalah terdapat perbedaan yang signifikan antara skor posttest pada kelompok eksperimen dan kelompok kontrol. Selain itu peneliti melakukan analisis kembali dengan menggunakan uji statistic Wilcoxon untuk mengukur skor pretest dengan posttest pada kelompok eksperimen, menghasilkan nilai Z ebesar -3.482 dengan nilai Asymp. Sig. (2-tailed) sebesar .000 $(p<0.05)$ sehingga dapat disimpulkan bahwa pelatihan teknik sinema edukasi memberikan pengaruh yang signifikan dalam meningkatkan empati pada siswa smp pelaku perundungan. Kesimpulan ini didukung juga dengan 
hasil analisis uji statistik Wilcoxon yang tidak menunjukkan perbedaan signifikan antara skor pretest dan posttest pada kelompok kontrol, hasil analisis tersebut menunjukkan nilai Z sebesar .250 dengan nilai Asymp. Sig. (2-tailed) sebesar .803 ( $>0.05)$. Berdasarkan berbagai hasil beberapa uji statistik maka peneliti menarik kesimpulan hipotesis pada penelitian ini diterima, yaitu pelatihan teknik sinema edukasi efektif meningkatkan empati pada siswa smp pelaku perundungan.

Setelah satu minggu setelah pemberian intervensi (follow up) dilakukan pengukuran kembali untuk melihat dampak pemberian intervensi yang diberikan kepada peserta. Peneliti menggunakan uji statistik Wilcoxon untuk menganalisis data follow up terhadap skor posttest. Hasil uji statistik antara skor follow up dengan posttest pada kelompok kontrol yaitu nilai $\mathrm{Z}$ sebesar -.187dengan nilai Asymp. Sig. (2-tailed) sebesar .852 ( $>0.05$ ) sedangkan pada kelompok eksperimen memiliki nilai nilai nilai $Z$ sebesar -3.310 dengan nilai Asymp. Sig. (2-tailed) sebesar $.001(p<0.05)$.

Berdasarkan data diatas dapat ditarik kesimpulan bahwa pemberian intervensi berupa pelatihan teknik sinema edukasi selain mampu meningkatkan empati pada siswa smp pelaku perundungan juga memiliki kerberlanjutan dampak pada subjek minimal satu minggu setelah pemberian intervensi.

\section{DISKUSI}

Penelitian ini dilakukan untuk mengetahui efektivitas pemberian teknik sinema edukasi untuk meningkatkan empati pada siswa SMP pelaku perundungan. Berdasarkan analisis uji hipotesis maka diperoleh hasil bahwa pemberian pelatihan teknik sinema edukasi efektif meningkatkan empati pada siswa smp pelaku perundungan. Hal tersebubt sesuai dengan penjelasan dari Bryne (2003) menjelaskan bahwa empati seseorang akan muncul ketika ia melihat karakter fiktif dalam film yang menyerupai kehidupan sehari-hari, misalnya melihat peran tokoh korban perundungan. Setelah melihat film maka akan memunculkan perasaan efek positif. Oleh karena itu menonton film dapat memberikan efek positif yang dapat meningkatkan empati (Niemiec, 2011). Hasil penelitian yang dilakukan Tri (2017) memaparkan bahwa sinema terapi dapat meningkatkan empati siswa.

Selain data kuantitatif, peneliti juga menganalisis data kualitatif yang ada melalui kesimpulan hasil data kualitatif. Terdapat kesamaan hasil evaluasi dari peserta pelatihan saat try out modul dan pelaksanaan intervensi. Pada aspek materi yang paling menarik, saat try out materi "menonton film" mendapatkan presentase terbanyak yakni $60 \%$ dan saat pelaksanaan intervensi materi menonton film juga mendapatkan persentase terbanyak yakni $40 \%$. Selain itu materi "bagaimana empatiku" saat try out mendapatkan persentase $15 \%$ dan saat intervensi $20 \%$. Peneliti menganalisis data tersebut dengan menggunakan padangan (Bryne, (2003) menjelaskan bahwa empati seseorang akan muncul ketika ia melihat karakter fiktif dalam film yang menyerupai kehidupan sehari-hari, misalnya melihat peran tokoh korban perundungan. Setelah melihat film maka akan memunculkan perasaan efek positif. Oleh karena itu menonton film dapat memberikan efek positif yang dapat meningkatkan empati (Niemiec, 2011). Hasil penelitian yang dilakukan oleh Tri (2017) memaparkan bahwa sinema terapi dapat meningkatkan empati siswa. Hal tersebut di dukung oleh Arsyad (2016) dalam bukunya menjelaskan bahwa salah satu cara yang digunakan untuk menambah kadar empati seseorang melalui fungsi kognitif dan afektif adalah salah satu dari fungsi film sebagai media alternatif pembelajaran.

Materi yang paling bermanfaat saat try out yakni "bagaimana empatiku mendapatkan persentase kedua terbesar sebesar $37 \%$ sedangkan saat intervensi materi tersebut mendapat 
persentase terbesar yakni sebesar $35 \%$. Pelatihan teknik sinema edukasi mengajak peserta untuk memodeling beberapa adegan dalam film seperti bagaimana jika mereka bersikap dan merasakan menjadi korban perundungan atau ketika mereka berimanjinasi menjadi pelaku perundungan dalam film tersebut.Sehingga aspek aspek empati yang diungkapkan oleh Davis (1983) terdiri atas perspective taking, fantasy, empaty concern dan personal distress dapat tersampaikan.

Materi yang paling aplikatif yakni saat try out karena materi bisa di contoh dan langsung diterapkan sebesar $38 \%$ saat intervensi di setiap sesi ada contoh dan bisa diterapkan mendapatkan persentase sebanyak $20 \%$. Selain itu alasan lain yakni karena setelah menonton film ada keinginan dari peserta try out untuk merubah perilaku sebanyak $25 \%$ sedangkan pada peserta intervensi sebesar $20 \%$. Hal tersebut sejalan dengan pendapat Alwisol (2014) proses belajar akan berhasil jika di dalamnya terdapat pemroses informasi melalui meniru (modelling) hal tersebut dikarenakan meniru perilaku dari model atau tokoh adalah kekuatann terutama dalam pembelajaran melalui gaya observasi. Ketika seseorang belajar dengan cara meniru maka ia harus meniru, memperhatikan serta mempersepsikan sikap dan perilaku model tersebut disesuaikan dengan pengalaman yang mereka miliki. Sehingga seseorang dapat menarik kesimpulan berdasarkan pengalaman yang dimiliki apakah perilaku yang selama ini dilakukan membawa akibat yang positif atau negatif (Santrock, 2014). Film dapat memberikan pengaruh afektif khususnya dalam hal emosi sehingga beberapa kasus dapat memberikan stimulus motivasi dan penyemangat untuk mengikuti apa yang dilakukan oleh tokoh dalam film tersebut. Film menjadi salah satu metode untuk merancang perubahan sikap individu atau kelompok yang ingin dipengaruhi (Auliyah \& Flurentin, 2016).

Hasil observasi pada saat pelaksanaan intervensi terdapat 1 peserta yakni subjek WH yang kurang menunjukkan sikap antusias, kurang memberikan respon kepada fasilitaor, kurang aktif saat ada tugas diskusi dan tidak melaporkan hasil pekerjaan diskusinya kepada fasilitator akan tetapi data tersebut berbeda dengan data perubahan skor pretest dan posttest subjek yang menujukkan selisih perubahan skor (gain skor) sebesar $=6$. Sedangkan terdapat 1 subjek yakni subjek AW yang mendapatkan hasil yang sama antara data observasi pada saat pelaksanaan intervensi dengan perubahan skor pretest dan posttest yang menujukkan selisih perubahan skor (gain skor) yang cukup tinggi sebesar $=5$. Hal tersebut diketahui bahwa subjek WH perempuan sedangkan subjek AW laki-laki. Taufik (2012) menjelaskan bahwa gender menjadi salah satu hal yang memberikan pengaruh pada kemunculan empati. Perempuan memiliki kemampuan lebih cepat dan mudah untuk merasakan keadaan emosi seseorang daripada laki-laki. Supeni (2014) juga mengaskan bahwa salah satu hal yang mempengaruhi empati yaitu gender.

Berdasarkan hasil analisis catatan pelanggaran BK sebelum diberikan pelatihan teknik sinema edukasi mayoritas perilaku perundungan paling banuak dilakukan oleh subjek berjenis kelamin laki-laki daripada perempuan. Bentuk perundungan yang dilakukan oleh subjek berjenis kelamin laki-laki lebih banyak berupa perundungan fisik sedangkan perempuan lebih banyak perundungan bentuk verbal dan sosial. Hasil penelitian Gini, Albiero, Benelli, \& Altoe (2007) menunjukkan perilaku perundungan berhubungan dengan rendahnya tingkat empati pada pelaku perundungan berjenis kelamin laki-laki. Betanova \& Loukas (2014) berpendapat bahwa faktorfaktor emosional sangat relevan untuk menginformasikan bagaimana kemampuan keterampilan sosial-kognitif yang kurang optimal pada seorang remaja, dapat menyebabkan seseorang akan bersikap agresi dan berujung dengan munculnya perilaku perundungan dan intimidasi.

Sedang jika berdasarkan hasil matriks lembar kerja terdapat beberapa hal yang menjadi point yakni, pada perasaan peserta setelah menonton film lebih banyak menujukkan perasaan afektif seperti sedih, kasihan, menyesal, introspeksi diri dan marah. Sinema Edukasi menjadi sarana untuk 
memunculkan keadaan emosional seseorang dari sudut pandang yang berbeda sehingga dapat digunakan untuk meningkatkan empati (Tri, 2017). Hal tersebut didukung oleh Arsyad (2016) dalam bukunya menjelaskan bahwa salah satu cara yang digunakan untuk menambah kadar empati seseorang melalui fungsi kognitif dan afektif adalah salah satu dari fungsi film sebagai media alternatif pembelajaran. Colley (1998) bahwa empati termasuk dalam aspek afektif (kepedulian, kepekaan, berbagi pengalaman yang tidak baik) yang berfungsi untuk menselaraskan pengalaman emosional diri sendiri kepada pada orang lain. Taufik (2012) menambahkan bahwa empati afektif yakni adanya kesamaan pengalaman emosi seseorang dengan yang dirasakan oranglain. Pada perasaan peserta ketika menjadi tokoh dalam film muncul perasaan marah, sedih, bangga dan tidak terima. Keberhasilan munculnya perasaan tersebut karena di dalamnya peneliti berusaha mengungkapkan salah satu aspek empati yakni fantasy.

Aspek fantasy adalah keadaan inidvidu untuk berimajinasi baik secara kognitif maupun afektif biasanya diambil dari sikap dari para tokoh imajinatif di buku, film atau permainan sehingga individu dapat menempatkan diri dan tersentuh dengan perasaannya terhadap tindakan oranglain (Davis, 1983). Permasalahan perundungan terbesar yang dilakukan yakni dengan mengejek nama orangtua sebesar $36 \%$. Rachmah (2016) menambahkan yakni empati yang rendah berpengaruh terhadap karakteristik pelaku perundungan sehingga ia kurang mampu menghargai kondisi emosional orang oranglain terhadap perilaku perundungan yang mereka lakukan. Bentuk perundungan yang terjadi adalah perundungan fisik dan verbal. Coloroso (2007) dalam bukunya "Stop Bullying" menjelaskan bentuk penindasan yakni ada penindasan verbal seperti menghina dengan memberikan label nama, kritik tajam, mencela dan memfitnah. Serta sasarn utama perundungan adalah teman sekelas sebesar $80 \%$ dengan alasan balas dendam sebesar $49 \%$. (Storey, Slaby, Adler, Minotti, \& Katz (2008) mengungkapkan bentuk perilaku perundungan sebagai suatu bentuk penyalahgunaan reaksi emosional seseorang yang tidak tepat sehingga memiliki karakteristik "pengulangan", yakni seringkali sasaran perundungan adalah orang yang sama.

\section{KESIMPULAN}

Intervensi pelatihan teknik sinema edukasi efektif untuk meningkatkan empati pada siswa smp pelaku perundungan. Teknik Sinema Edukasi meangkat modelling sebagai dasar utama terbentuknya pencegahan perilaku perundungan di kalangan siswa SMP. Model dalam modelling ini yakni tokoh dalam film. Sinema edukasi menjadi media intervensi dalam penelitian ini. Ada 4 sesi dalam pelatihan ini yang berpengaruh dalam peningkatan empati pada peserta intervensi yakni "bagaimana empatiku, mendalami empati, strategi penyelesaian konflik dan rencana tindakan".Sesi tersebut mewakili aspek-aspek yang ada dalam empati. Hasil dari lembar evaluasi dan lembar kerja peserta pelatihan teknik sinema edukasi mengubah pemikiran dan perilaku negatif peserta yang dulunya menyakiti orang lain untuk membalas dendam berubah menjadi kearah yang lebih positif dengan cara membuat target perilaku yang akan dirubah dan bercermin terhadap perilaku apa saja yang sudah berhasil dirubah dan tidak dirubah. Temuan dalam penelitian ini yang pertama adalah mayoritas peserta menyatakan bahwa sesi yang paling menarik dan bermanfaat dari pelatihan teknik sinema edukasi adalah menonton film. Kedua, adanya lembar kerja berupa "kartu kejujuran" dan "booklet action plan" membuat peserta lebih bisa mengungkapkan apa yang menjadi alasan sebenarnya perilaku mereka muncul serta mereka memiliki keinginan tersendiri untuk membuat target perubahan sikap yang harus diperbaiki dari hal kecil hingga hal besar. Ketiga gender, hal tersebut menunjukkan bahwa rata-rata mayoritas 
peserta perempuan memiliki empati yang lebih tinggi daripada laki-laki dilihat dari banyaknya jenis perundungan yang mereka lakukan. Hal keempat yang ada dalam pelatihan ini pencegahan yang dilakukan sejak sedini mungkin dapat mengurangi perkembangan perilaku perundungan yang semakin marak pada jenjang pendidikan yang selanjutnya, cara ini dapat digunakan sebagai solusi pembelajaran peningkatan empati di sekolah dengan cara yang menarik dan menyenangkan bagi siswa.

\section{DAFTAR PUSTAKA}

Aiken, L. R. (1985). Aiken, L. R. (1985). Three coefficients for analyzing the reliability and validity of ratings. , 45(1), 131-142. Educational and psychological measurement , 45 (1), 131-142.

Alwisol. (2014). Psikologi Kepribadian (Edisi Revisi). Malang: UMM Press.

Arsyad, A. (2016). Media Pembelajaran. Jakarta: Raja Grafindo Persada.

Auliyah, A., \& Flurentin, E. (2016). Efektifitas Penggunaan Media Film Untuk Meningkatkan Empati Siswa Kelas VII SMP. Jurnal Kajian Bimbingan dan Konseling , 1 (1), 19-26.

Azwar, S. (2012). Reliabilitas dan Validitas. Yogyakarta: Pustaka Pelajar.

Betanova, M., \& Loukas, A. (2014). Unique And Interactive Effects Of Empathy, Family, And School Factors On Early Adolescents' Aggression. Journal Of Youth And Adolescence, 43 (11), 1890-1902.

Bryne, B. D. (2003). Psikologi Sosial Jilid 2. Alih Bahasa Ratna Djuwita. Jakarta: Erlangga.

Chan, H. C., \& Wong, D. S. (2015). Chan, H. C. O., \& Wong, D. S. (2015). The overlap between school bullying perpetration and victimization: Assessing the psychological, familial, and school factors of Chinese adolescents in Hong Kong. x, 24(11). Journal of child and Family Studies , 24 (11), 3224-3234.

Colley, C. H. (1998). On Self and Social Organization. Chicago: University Of Chicago Press.

Coloroso, B. (2007). Stop bullying (memutus rantai kekerasan anak dari prasekolah hingga SMU). Jakarta: Ikrar : Mandiri Abadi.

Creswell, J. W. (20dded315). Research Design: Qualitative Quantitative and Mixed Metods Approaches. Singapura: SAGE Publication.

Davis, M. H. (1983). Measuring Individual Differences in Empathy : Evidence for Multidimensional Approach. Journal Of Child And Family Studies, 3224-3234.

Fikrie. (2016). Peran empati dalam perilaku bullying. Malang: Seminar Asean Psikologi Forum UMM.

Gini, G., Albiero, P., Benelli, B., \& Altoe, G. (2007). Does empathy predict adolescents' bullying and defending behavior? Aggresive Behavior: Official Journal Of the Internastional Society for Research on Agrression, 33 (5), 467-476.

Hawker, D. S., \& Boulton, M. J. (2014). Twenty years research on peer victimization and psychosocial maladjustment: A meta-analytic review of cross-sectional studies. Journal of child psychology and psychiartry, 41 (4), 441-445.

Irel, I. R. (2017). Hubungan sense of self dengan kecenderungan perilaku bullying pada siswa SMA di Jakarta . Psikodimensia , 16 (1), 91-106. 
Lessne, D., \& Cidade, D. (2015). Students reports of bullying and cyberbullying: Result from 2013 school crime supplement to the national crime victimization. Washington D.C: United States Department of Education.

Machackova, H., \& Pfetsch, J. (2016). Bystanders' Responses To Offline Bullying And Cyberbullying: The Role Of Empathy And Normative Beliefs About Aggression. Scandinavian Journal Of Psychology, 57 (2), 169-176.

Niemiec, R. M. (2011). Positive psychology cinemeducation: A review of Happy. International Journal Of Wellbeing , 1 (3).

Purnama, A. D. (2017). Hubungan Antara Pola Asuh Otoriter Dengan Perilaku Bullying Pada Siswa SMP N 24 Surakarta. Surakarta: Skripsi Tidak Diterbitkan. Fakultas Psikologi Universitas Muhammadiyah Surakarta.

Rachmah, D. N. (2016). Empati pada pelaku bullying. Jurnal Ecopsy, 1 (2).

Rismawan. (2016). KPAI: Angka kekerasan terhadap anak meningkat. Dipetik 2019, dari Tribun. Retrieved 2019, from Tribunnews.com: https://www.tribunnews.com/nasional/2016/05/06/kpai-angka-kekerasan-terhadap-anakmeningkat

Santrock, J. W. (2014). Psikologi Pendidikan Edisi 5 Jilid 1. Jakarta: Salemba Humanika.

Sari, H. N., Joefiani, P., Gimmy, A., \& Siswadi, P. (2015). Pelatihan meningkatkan empati melalui psikoedukasi kepada pelaku bullying sebagai upaya untuk mengurangi bullying di sekolah menengah pertama. Bandung: Repository Unpad Ac. Id.

Stanbury, e. a. (2009). ). The Effect Of An Empathy Building Program On Bullying Behavior On Canadian. Journal Of Psychiarty, 48 (1), 577-582.

Storey, K., Slaby, R., Adler, M., Minotti, J., \& Katz, R. (2008). Eyes on Bullying. What can you do. A toolkit to prevent bullying in children's lives. Waltham: Education Development Center.

Sujarweni, V. W. (2014). Metodologi Penelitian; Lengkap dan Mudah Dipahami. Yogyakarta: Pustaka Baru Press.

Supeni, M. G. (2014). Empati Perkembangan dan Pentingnya dalam Kehidupan Bermasyarakat. Jurnal Psikologi Universitas Tidar Magelang , 40 (1), 60-71.

Taufik, K. (2012). Empati: Pendekatan Psikologi Sosial. Jakarta: Raja Grafindo.

Tri, J. Y. (2017). Penerapan Cinema Therapy untuk Meningkatkan Empati Siswa Kelas X Multimedia di SMKN 1 Driyorejo. Jurnal BK UNESA .

Wang, J., Iannotti, R. J., \& Nansel, T. R. (2009). School bullying among adolescents in the United States: Physical, verbal, relational, and cyber. Journal of Adolescent health , 45 (4), 368375.

Wewengkang, D. B. (2018). Efektifitas Pelatihan Empati Untuk Menurunkan Perilaku Perundungan (Bullying) Pada Siswa SMK Wonogiri. Surakarta: Tesis Tidak Dipublikasikan (Universitas Muhammadiyah Surakarta).

Wu, A. Z. (2008). Applying cinema therapy with adolescents and a cinema therapy workshop. East Bay: California State University.

Zakiyah, E. Z., Humaedi, S., \& Santoso, B. M. (2017). Faktor Yang Mempengaruhi Remaja Dalam Melakukan Bullying. , 4(2). Jurnal Penelitian \& PPM , 4 (2). 